\section{CITAÇÃO}

Carvalho, M.L., Manso, M.,

Pessanha, S. (2018)

Os Raios X na Arte e no Património

Cultural,

Rev. Ciência Elem., V6(01):019.

doi.org/10.24927/rce2018.019

\section{EDITOR}

José Ferreira Gomes,

Universidade do Porto

\section{EDITOR CONVIDADO}

Luís Vítor Duarte,

Universidade de Coimbra

\section{RECEBIDO EM}

12 de fevereiro de 2018

\section{ACEITE EM}

03 de março de 2018

\section{PUBLICADO EM}

14 de março de 2018

\section{COPYRIGHT}

(C) Casa das Ciências 2018.

Este artigo é de acesso livre, distribuído sob licença Creative Commons com a designação CC-BY-NC-SA 4.0, que permite a utilização e a partilha para fins não comerciais, desde que citado o autor e a fonte original do artigo.

rce.casadasciencias.org

\title{
Os Raios X na Arte e no Património
}

\section{Cultural}

Maria Luisa de Carvalho, Marta Manso, Sofia Pessanha

LIBPhys-UNL / Departamento de Física Universidade Nova de Lisboa

luisa.carvalho@fct.unl.pt

0 tema principal deste trabalho é dar a conhecer o trabalho científico que temos feito por aplicação dos raios $X$ ao estudo de obras de Arte, incluindo documentos de papel com valor histórico-cultural.

Os raios $X$ são radiação eletromagnética, que se distinguem da luz visível apenas porque a radiação $X$ tem uma energia muito superior à da radiação visível. Esta característica confere aos raios $X$ propriedades especiais, tais como o elevado poder de penetração na matéria e 0 poder de ionizar os átomos nos níveis internos. Para além disso, esse poder de penetração, ou poder de absorção de cada elemento, como se lhe queira chamar, é característico de cada elemento. É isso que nos permite distinguir os ossos numa radiografia.

0 poder de ionização é a propriedade que permite ionizar, ou seja arrancar um eletrão, aos átomos do material onde incidem os raios $X$, com total absorção da energia do fotão incidente. Este é o chamado efeito fotoelétrico, cuja explicação se deve a Einstein (FIGURA 1).

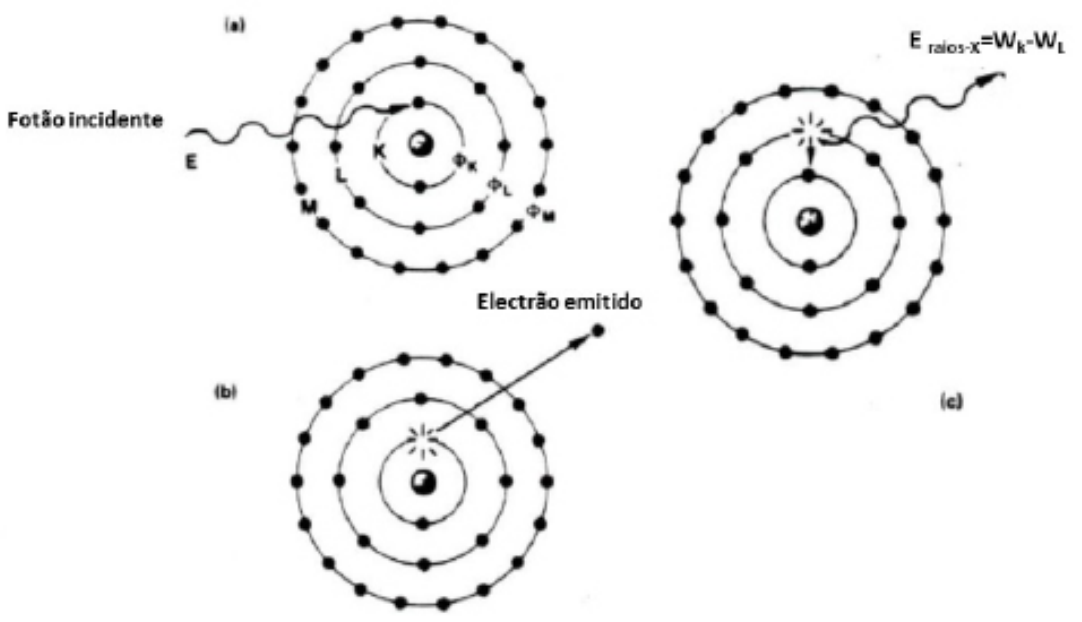

FIGURA 1. Reorganização do átomo após ionização devida à radiação X incidente. A radiação emitida é característica do átomo e dos níveis entre os quais se deu a transição. 
0 átomo é ionizado num nível profundo por absorção dum fotão da radiação $\mathrm{X}$ incidente. Este átomo ionizado fica num estado instável e rapidamente um eletrão dum nível exterior vai ocupar a lacuna interior deixada pelo eletrão arrancado. Como resultado desta transição o átomo pode emitir radiação, sendo esta radiação característica de cada elemento, pois é igual à diferença de energia dos níveis entre os quais se deu a transição.

Nestas condições, se tivermos um detetor de radiação $X$, podemos identificar a energia da radiação emitida por cada átomo e deste modo identificar o elemento. Este é o $1^{\circ}$ passo para a identificação dos elementos constituintes de um objeto. Esta técnica é usualmente designada por Fluorescência de Raios X. Dá-se o nome de espectro, ao gráfico que nos dá o número de contagens em função da energia (FIGURA 2).

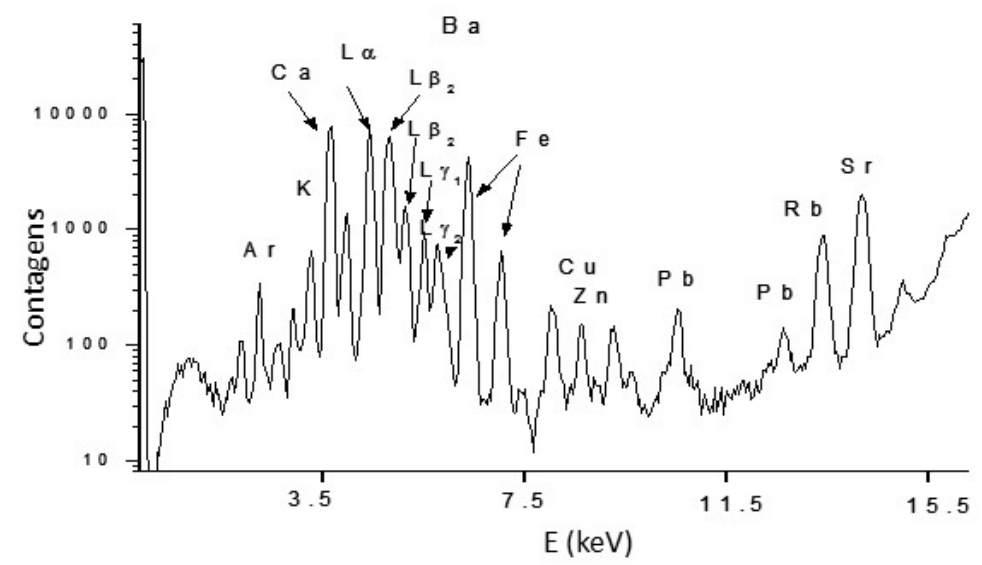

FIGURA 2. Espectro emitido pela amostra, que nos permite identificar os elementos presentes.

A Fluorescência de Raios X (XRF) é uma técnica muito utilizada e é uma ferramenta simples para estudar a composição elementar dos materiais, pois permite a análise não destrutiva dos objetos sem necessidade de retirar uma amostra. Nos últimos anos desenvolveram-se equipamentos portáteis que permitem fazer este estudo in situ, ou seja, deslocar os equipamentos aos locais de interesse, permitindo o estudo de objetos que não podem ser removidos do seu local original devido ao seu peso, dimensões, estado de conservação, ou devido ao seu valor.

Em alguns casos a identificação dum elemento é suficiente para nos dar a informação pretendida. Este é o caso por exemplo da presença de zinco no espectro emitido pela cor branca duma pintura. Trata-se do branco de zinco, um composto à base de zinco, que apenas começou a ser utilizado a partir de 1834. Neste caso a presença deste pigmento indica que a obra tem que ser posterior a esta data. Os brancos anteriores eram à base de chumbo, que apesar da toxicidade do chumbo continuam a ser utilizados na atualidade.

Mas em muitos casos a identificação do elemento não é suficiente para caracterizar completamente a nossa amostra. Estes casos são sobretudo quando se trata de amostras biológicas, amostras ambientais ou casos de toxicologia. Saber que um dado elemento está presente não é suficiente. É necessário saber em que quantidade. E porque é que saber a quantidade é importante? Todos os elementos são potencialmente tóxicos, aquilo que o dis- 
tingue dum medicamento é a sua concentração. Isto significa que alguns elementos são tóxicos mesmo quando estão presentes em baixa concentração, tal é o caso do chumbo nos alimentos ou no ar que respiramos. Outros são tóxicos a partir de concentrações muito elevadas nos alimentos, tal é o caso do ferro ou do zinco.

Também nas obras de arte, por vezes, saber a concentração dum dado elemento é imprescindível para a sua caracterização, como por exemplo objetos de ouro que apresentam uma percentagem de cobre e prata. Podem ainda existir no ouro elementos em muito baixa concentração, elementos traço, resultantes do processo de fabrico ou impurezas que resultam da proveniência do ouro e saber as concentrações pode ser a peça chave para a identificação, processos de fabrico ou proveniência. Pode ainda tratar-se da identificação de um documento através da caracterização da sua tinta, ou de um documento de papel para saber a sua origem.

Esta técnica é quantitativa e permite, em muitos casos determinar a concentração de cada elemento na amostra.

A intensidade da radiação emitida $I_{i}$ por cada elemento está relacionada com a quantidade em que esse elemento está presente na amostra, ou seja, a sua concentração $C_{i}$, através da expressão:

$$
I_{i}=I_{0} K_{i} A_{i} C_{i}
$$

Depende ainda da energia da radiação incidente, da energia da radiação emitida pelo elemento, dos ângulos que as radiações incidente e emitida fazem com a amostra, do coeficiente de atenuação do elemento $i$ para a energia da radiação incidente, e do coeficiente de atenuação do elemento para as energias emitidas pelos restantes elementos presentes na amostra.

$O$ fator $K_{i}$ tem em conta os parâmetros característicos da montagem experimental (ângulo sólido do detetor, a eficiência do detetor para cada radiação, a absorção da radiação na janela do detetor e no ar e os parâmetros fundamentais característicos de cada elemento: o rendimento de fluorescência, a probabilidade de ionização, e a probabilidade de transição, do nível inicial para o nível final do elemento.

Todos os parâmetros nesta expressão são conhecidos para cada elemento e para uma dada montagem experimental, exceto o fator $A_{i}$ que corresponde à absorção da radiação na amostra. 0 grande desafio do Físico é obter esta concentração utilizando vários métodos, que podem ser mais ou menos difíceis.

\section{Aplicação ao estudo de Biombos Namban}

A arte Namban consiste na corrente artística despoletada pela chegada dos Portugueses (bem como outros navegadores Europeus) ao Japão em 1543, que retrata estes Nambanjin ou "Bárbaros vindos do Sul", com narizes proeminentes e trajes berrantes a desembarcar nos portos Japoneses. Os mais importantes exemplos deste movimento artístico existentes em Portugal são os pares de biombos em papel pintado e dourado, existentes no Museu Nacional de Arte Antiga (MNAA) e Museu Oriente (MO) em Lisboa e no Museu Nacional Soares dos Reis (MNSR), no Porto. Todos foram estudados por nós e as conclusões mereceram publicação em revistas internacionais. Os resultados obtidos foram importantes para a identificação dos pigmentos e para caracterizar a técnica de execução, nomeadamente que a folha 
de ouro só tinha sido aplicada fora das áreas pintadas, contrariamente à ideia dos conservadores do Museu, que consideravam que a folha de ouro cobria toda a área do biombo. Foi ainda determinada a espessura da folha de ouro. Tipicamente estas peças foram criadas por artistas contemporâneos à chegada dos Portugueses ao Japão, utilizando pigmentos à base de minerais existentes na região. Muitas peças foram criadas posteriormente, como exercício académico mesmo depois da expulsão dos Jesuítas um século depois. 0 nosso estudo consistiu na identificação dos pigmentos.

Sobre o par de biombos do MNSR (FIGURA 3), residiam dúvidas acerca dos procedimentos utilizados numa campanha de restauro não documentada, efetuada em data anterior à compra dos biombos pelo estado Português em 1955 e que teria deixado um revestimento brilhante sobre toda a extensão dos biombos. De modo a perceber quais os materiais utilizados nessa campanha de restauro do par de Biombos atribuídos ao Mestre Kanō Mitsunobu, procedeu-se à análise in situ do par de biombos no MNSR por Fluorescência de Raios X. Relativamente aos tons rosa e avermelhados, a presença de $\mathrm{Hg}$ desde logo indicou a utilização do pigmento vermelhão ( $\mathrm{HgS}$ ) misturado com Ca para aclarar. $\mathrm{O} \mathrm{CaCO}_{3}$ é o composto tipicamente encontrado nos tons brancos da arte japonesa desta época, devido à utilização de conchas esmagadas para produzir o pigmento gofun. Por outro lado, elementos como $\mathrm{Cr}$, $\mathrm{Ba}$ e Co, frequentes em pigmentos sintéticos modernos, foram desde logo identificados em regiões de tom amarelo, laranja, castanho e azul. Relativamente aos pigmentos azuis, para além da azurite, foram identificados azul de cobalto e azul de ftalocianina. 0 azul de cobalto foi descoberto em 1802, havendo apenas registos do seu uso na pintura tradicional japonesa após a II Guerra Mundial levando a considerar que esse pigmento não fazia parte da obra de arte original. 0 mesmo pode ser dito em relação ao azul de ftalocianina, um corante orgânico com uma cor muito intensa. 0 azul de ftalocianina foi desenvolvido por químicos da Imperial Chemical Industries, Ltd, em meados da década de 1930, tornando-se comercialmente disponível no início de 1938. Desta forma, podemos concluir que a intervenção de restauro desconhecida não poderia ter sido realizada antes desta data.

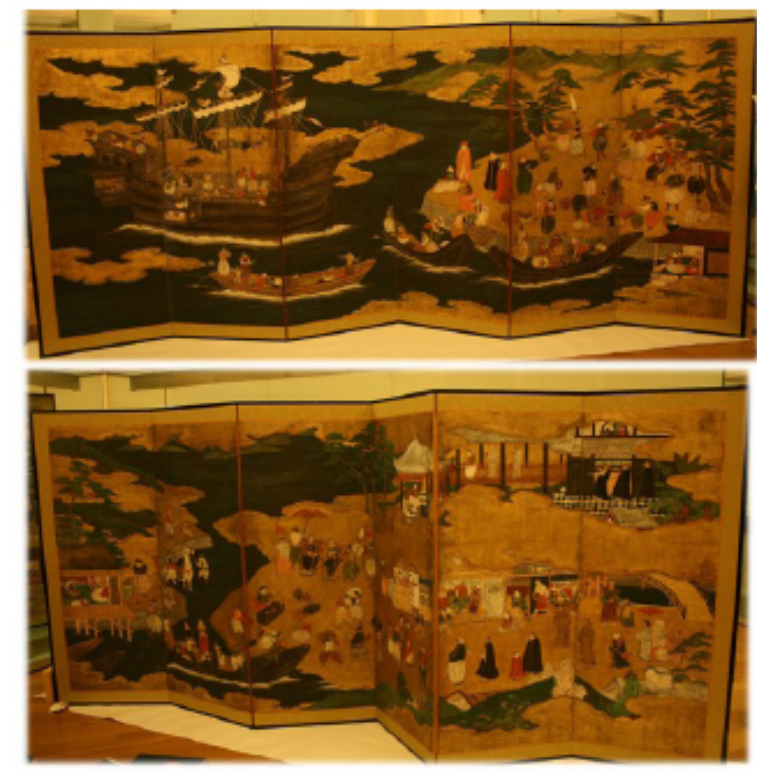


Relativamente aos tons amarelos, o pigmento típico da paleta Namban é o ocre. No entanto, nestas obras foi identificado o amarelo de crómio. Trata-se de um pigmento moderno que só apareceu nas pinturas japonesas tradicionais na era Meiji (1868-1912). Estes pigmentos à base de cromato de chumbo são muito instáveis e tendem a oxidar e escurecer com a exposição ao ar ao longo do tempo. Por esse motivo estes pigmentos foram sendo substituidos por outros, como o amarelo de cádmio (CdS), que se supunha serem mais estáveis. Isso significa que a intervenção deve ter sido realizada imediatamente antes dos pigmentos de cromato de chumbo entrarem em desuso, provavelmente na década de 1940 ou no início dos anos 1950, antes do estado português ter adquirido os Biombos Namban em 1955.

\section{Estudo da 3a parte do Segredo de Fátima}

Pela primeira vez, o documento selado (FIGURA 4) contendo a 3a parte do Segredo de Fátima, escrito pela Irmã Lúcia a 3 de janeiro de 1944 e enviado para o Vaticano em 1947, onde esteve guardado até 2016 no arquivo da Congregação para a Doutrina da Fé, foi submetido a análises científicas não invasivas.

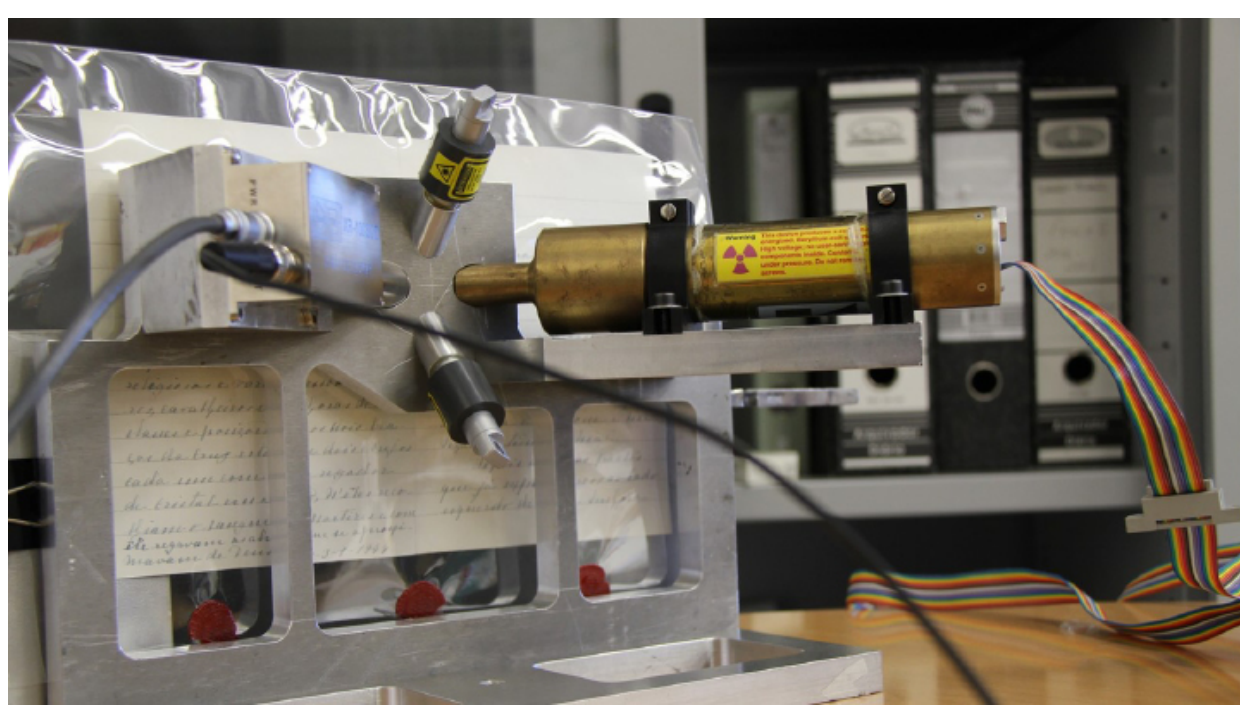

FIGURA 4. 3os segredo de Fátima, selado, ao ser analisado no laboratório.

Este documento veio para Portugal para integrar a exposição "Segredo e Revelação", no Santuário de Fátima. Antes de regressar ao Vaticano, o documento permaneceu dois dias no Laboratório de Física Atómica e Molecular, na Faculdade de Ciências e Tecnologia, Universidade Nova de Lisboa, onde foi analisado com equipamento de Fluorescência de Raios $X$.

0 objetivo deste trabalho teve em vista a caracterização do papel e da tinta e os resultados obtidos foram comparados, com os de outros documentos da época, obtidos pela mesma técnica, escritos pela Irmã Lúcia antes e após a escrita deste documento, para certificação. Deste estudo fez ainda parte a análise dos documentos da $1^{\underline{a}}$ e $2^{\underline{a}}$ parte do Segredo de Fátima.

Foi utilizada a técnica analítica Fluorescência de raios-X (FRX) para identificar e quantificar os elementos que integram a composição química dos documentos em estudo. $O$ objetivo do trabalho era a certificação do documento que revela o Terceiro Segredo de Fátima, por com- 
paração com outros quatro documentos escritos e assinados pela Irmã Lúcia durante o mesmo período, através da composição do papel e das tintas utilizadas nos vários documentos.

Estes outros documentos eram: cartas dirigidas a amigas, uma de 17 de novembro de 1943 , duas de 1944, uma datada de 8 de janeiro e a outra de 27 de fevereiro, respetivamente e um bilhete-postal de 26 de novembro de 1943.

Foram ainda analisados os fólios 2 e 3 e o fólio 7, datados de 1941, com as memórias das aparições, com descrição do que se considera o primeiro e o segundo segredos e um caderno com várias folhas, escrito em 1922, poucos anos após as aparições, o primeiro documento escrito pela Irmã Lúcia em que descreve os acontecimentos das aparições.

Da análise do papel de todos os documentos verificou-se que estes possuíam na sua composição elementos maioritários como o enxofre $(\mathrm{S})$, o potássio $(\mathrm{K})$ e o cálcio $(\mathrm{Ca})$, os quais são adicionados como cargas (ex. sulfato de cálcio $\left(\mathrm{CaSO}_{4}\right)$, calcite $\left(\mathrm{CaCO}_{3}\right)$, dolomite $(\mathrm{CaM}$ $\left.\mathrm{g}\left(\mathrm{CO}_{3}\right)_{2}\right)$ assim designadas por preencherem os espaços vazios entre as fibras de celulose, usada no fabrico do papel. A adição de cargas pode também conferir ao papel brilho, opacidade, suavidade e melhor absorção da tinta. Estas cargas dependem do fabricante do papel, razão pela qual as quantidades de $\mathrm{S}, \mathrm{K}$, Ca podem ser diferentes entre os papéis dos vários documentos. Porém, são os elementos vestigiais, cuja presença no papel é efetivamente acidental, que permitem caracterizar e identificar um determinado tipo de papel.

Da análise dos vários documentos verificámos que os papéis utilizados pela Irmã Lúcia são todos diferentes uns dos outros. 0 diagrama ternário apresentado na FIGURA 5 permitiu-nos concluir que os cinco documentos analisados possuem diferentes proporções de cálcio (Ca), ferro (Fe) e zinco (Zn).

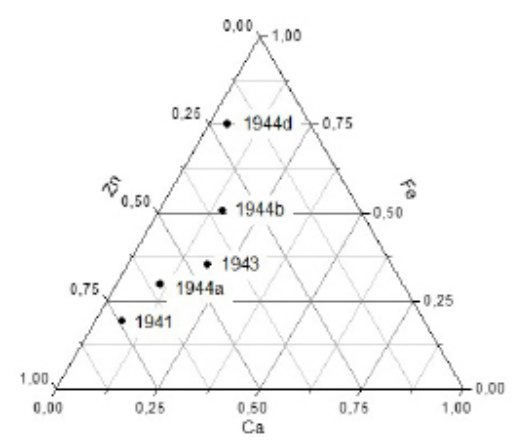

\begin{tabular}{|l|l|l|}
\hline Legenda & Documento & Data \\
\hline $\mathbf{1 9 4 1}$ & Fólios 2, 3 e 7 & 1941 \\
\hline $\mathbf{1 9 4 3}$ & Carta amiga & 17 Nov 1943 \\
\hline $\mathbf{1 9 4 4 a}$ & Carta amiga & 3 Jan 1944 \\
\hline $\mathbf{1 9 4 4 b}$ & Terceiro Segredo & 8 Jan 1944 \\
\hline $\mathbf{1 9 4 4 C}$ & Carta amiga & 27 Fev de 1944 \\
\hline
\end{tabular}

FIGURA 5. Tabela dos documentos analisados e diagrama ternário com as concentrações elementares de Ca, Fe e Zn.

De acordo com esta conclusão, a identificação do papel não permite provar que o documento tenha sido escrito pela irmã Lúcia, pois ela usava papéis de carta diferentes e não um único, como inicialmente tínhamos previsto.

Restou-nos, pois, a tinta utilizada, a qual se revelou constituir uma grande prova. As tintas para escrita são compostas por corantes ou pigmentos que the conferem a cor, um solvente e aditivos responsáveis pelas suas propriedades físico-químicas. São os elementos inorgânicos vestigiais que podem identificar uma dada tinta. 0 único elemento inorgânico detetado nas tintas analisadas foi o zinco que, apesar de se encontrar também presente no papel, se 
encontra em muito maior quantidade nas tintas. Podemos inferir, então, que o tom azul foi obtido pela adição de um corante pois o $\mathrm{Zn}$ não confere cor à tinta, podendo alterar as suas propriedades físico-químicas.

A tinta utilizada na escrita de todos os documentos continha o mesmo elemento, zinco, e a concentração de zinco era a mesma em todas as tintas de todos os documentos de 1943 e 1944, incluindo a utilizada no Terceiro Segredo. Podemos concluir que a tinta utilizada era a mesma em todos os documentos.

Nos documentos de 1941 a tinta também continha zinco, mas com uma concentração diferente. Para tornar este estudo mais conclusivo foram estudados os documentos escritos pela Irmã Lúcia em 1922 e vimos que a tinta era bem diferente da utilizada nos documentos de 1943 e 1944 e não continha zinco.

Outro objetivo era garantir a integridade do documento, ou seja, garantir que o documento não foi alterado ou rasurado após ter sido escrito e ter sido reconhecido pela própria Irmã Lúcia, como sendo o documento que ela tinha escrito em 1944 e enviado ao Bispo a revelar o $3^{\circ}$ segredo; esse documento, apenas está datado, mas não assinado. Tal foi concretizado através de uma análise de varrimento de todo o documento efetuada com um equipamento de micro-Fluorescência de Raios X. Está ilustrado na FIGURA 3 um exemplo do mapeamento do zinco, no Terceiro Segredo feito para uma zona que contém a data e como se pode verificar na imagem (FIGURA 6), pode identificar-se perfeitamente a escrita contida no retângulo do documento.
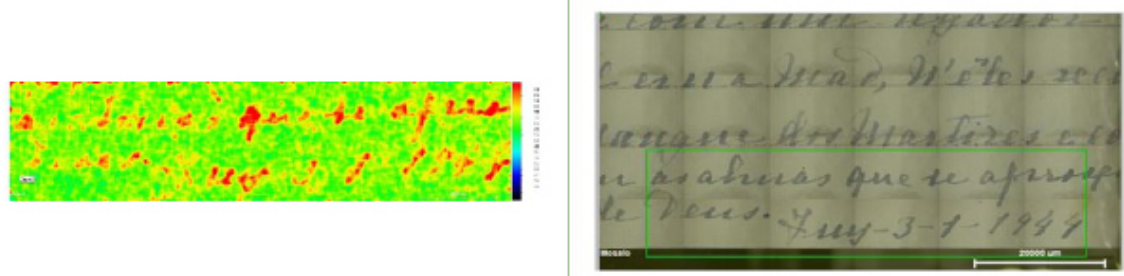

FIGURA 6. Mapeamento do Zn duma parte do 3ํ Segredo de Fátima.

\section{Arqueologia}

A aplicação de Fluorescência de Raios $X$ mostrou-se também bastante útil na análise de amostras arqueológicas. Estudou-se um conjunto de restos mortais exumados da Ermida do Espírito Santo (Almada). A Ermida foi construída no século 15 e de acordo com os registros da paróquia de Santa Maria do Castelo, foi utilizada como local de enterramento durante 78 anos, desde 1755, após o terramoto que destruiu particamente todas as igrejas da zona, até 1834 após a saída do decreto que proíbia os enterramentos dentro das igrejas. Em 2011, durante escavações arqueológicas, recuperaram-se os restos de 83 indivíduos. Neste trabalho, referimos a análise elementar dos restos de um indivíduo específico, principalmente cabelo e ossos, com ênfase na presença de quantidades extremamente elevadas e invulgares de mercúrio no cabelo. Trava-se de um adulto do sexo feminino, com aproximadamente 50 anos 
de idade, enterrada com uma mortalha, sem caixão e a cerca de $70 \mathrm{~cm}$ de profundidade. As amostras analisadas foram: uma mecha de cabelo, um dente molar e ossos pertencentes ao crânio, costelas e falange da mão. Para avaliar possíveis contaminações externas, analisou-se também o solo circundante.

0 resultado mais expressivo obtido neste estudo foi a extraordinária concentração de $\mathrm{Hg}$ nas amostras de cabelo de $6 \%$ (\% massa) FIGURA 7. Revelou-se fundamental perceber se a contaminação foi ante mortem ou post mortem. As análises obtidas pelo mesmo processo, para o solo recolhido do local da inumação não revelaram a presença de $\mathrm{Hg}$, mostrando que a contaminação terá sido ante mortem. A dúvida agora seria se a contaminação teria sido por via interna ou externa. Quanto aos restantes restos mortais, apenas foi detetado Hg no crânio e em quantidades muito inferiores (cerca de $40 \mu \mathrm{g} / \mathrm{g}$ ) sugerindo uma aplicação externa diretamente nos cabelos.

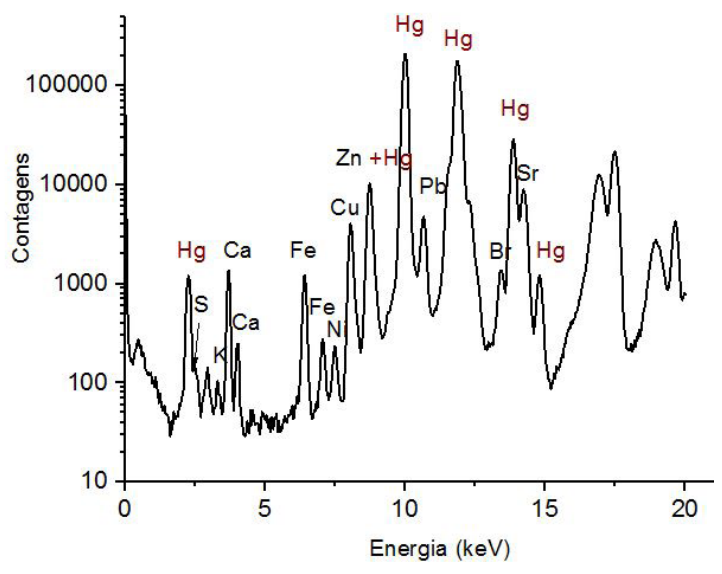

FIGURA 7. Espectro de cabelo pertencente aos restos mortais.

Uma possível explicação para a aplicação de mercúrio ao cabelo pode ser a sua utilização para tratamento de piolhos: amostras de cabelo de Ferdinand II de Aragão (1467-1496) mostraram um alto teor de mercúrio, com um valor de $827 \mu \mathrm{g} / \mathrm{g}$. Textos contemporâneos sobre Ferdinand mostram claramente que o mercúrio também foi frequentemente empregado em receitas cosméticas: o mercúrio e o sublimado foram incluídos na composição dos produtos utilizados para branquear a pele, ou para remover o eritema ou outras doenças da pele. Sendo o mercúrio um elemento altamente tóxico, a aplicação de uma quantidade tão elevada deste elemento pode ter originado a morte do paciente.

\section{REFERÊNCIAS}

\footnotetext{
${ }^{1}$ CARVALHO, M.L. et al., "A Física vai ao Museu", Gazeta de Física, 33, 1, 7-10, 2010.

${ }^{2}$ PESSANHA, S. et al., Elemental analysis by portable Ag and Rh x-ray sources of a Namban folding screen, Nuclear instruments and Methods in physics research B, 309, 254-259, 2013.

${ }^{3}$ PESSANHA, S. et al., Characterization of a Namban folding screen from the Edo period by means of EDXRF, SEM-EDS and Raman spectroscopy, X-Ray Spectrom, 42, 128-133, 2013.

${ }^{4}$ PESSANHA, S. et al., Evaluation of the intervention of a folding screen belonging to the Momoyama period by Raman spectroscopy using different wavelengths, Journal of Raman spectroscopy 43, 1699-1706, 2012.

${ }^{5}$ MANSO, M. et al., Unveiling the Third Secret of Fatima: micro-XRF quantitative characterization and 2D elemental mapping, Spectrochimica Acta B, 130, 35-38, 2017.

${ }^{6}$ MANSO, M. e CARVALHO, M.L., Elemental identification of document paper by X-ray fluorescence spectrometry,
} 
J. Anal. At. Spectrom. 22, 164-170, 2007.

${ }^{7}$ MANSO, M. et al., X-ray fluorescence spectrometry on paper characterization: case study on XVIII and XIX century documents, Spectrochimica Acta B 63, 1320-1323, 2008.

${ }^{8}$ CURATE, F. et al., Fracturas bilaterales de tibia y peroné en un individuo femenino de la «Ermida do Espírito Santo» (Almada, Portugal), Actas del XI Congreso Nacional de Paleopatología, 2011.

${ }^{9}$ FORNACIARI, G. et al., The Use of Mercury against Pediculosis in the Renaissance: The Case of Ferdinand II of Aragon, King of Naples. Medical History, 55: 109-115, 2011.

${ }^{10}$ PESSANHA, S. et al., Quantitative analysis of human remains from 18th-19th centuries using X-ray fluorescence techniques: The mysterious high content of mercury in hair, Journal of Trace Elements in Medicine and Biology 33, 26-30, 2016 